\title{
Commentary: With a median survival of only 2 to 3 years, should dialysis patients more than 50 years old exclusively have transcatheter valves?
}

\author{
Daniel T. Engelman, MD, and David W. Deaton, MD
}

\footnotetext{
From the Department of Surgery, Baystate Medical Center, Springfield, Mass; and the University of Massachusetts Medical School-Baystate, Springfield, Mass.

Disclosures: D.T.E. is a consultant for Astute Medical, on the Medical Advisory Board for PAVmed, and a consultant for Zimmer-Biomet. D.W.D. has nothing to disclose with regard to commercial support.

Received for publication Oct 22, 2018; accepted for publication Oct 22, 2018; available ahead of print Dec 6, 2018.

Address for reprints: Daniel T. Engelman, MD, 759 Chestnut St, Springfield, MA 01199 (E-mail: Daniel. Engelman@baystatehealth.org).

J Thorac Cardiovasc Surg 2019;158:816-7

$0022-5223 / \$ 36.00$

Copyright (c) 2018 by The American Association for Thoracic Surgery

https://doi.org/10.1016/j.jtcvs.2018.10.101
}

It is well known that patients on hemodialysis for end-stage renal disease have a poor long-term prognosis. ${ }^{1}$ These patients are especially prone to cardiovascular disease. ${ }^{2}$ Prosthetic valve selection for this population has remained controversial. Biologic valves may be prone to early calcification exacerbated by end-stage renal disease. ${ }^{3}$ Equally challenging, the anticoagulation requirements in this vulnerable population are substantial after implantation of mechanical valves.

In their retrospective review in this issue of the Journal, Manghelli and collegues ${ }^{4}$ compared postoperative outcomes of 423 patients from 3 institutions during a 20-year period who required preoperative hemodialysis and underwent valve replacement surgery with either biologic or mechanical valves. They compared 341 patients with a biologic valve with 82 patients with a mechanical valve. The average age of patients with a biologic valve was 60 years; that of those with a mechanical valve was 51 years.

The most striking result of this study was the tragically short lifespan of a dialysis-dependent patient after valve replacement surgery. Ten-year survivals for biologic and mechanical valves were $5 \%$ and $20 \%$, respectively, with median survivals of 2 and 3 years, respectively. When adjusted for all covariates, survival was similar between groups. These results are similar to previous smaller studies. 5

This study was limited by its retrospective nature, potential surgeon selection bias, and a lack of standardized protocols regarding which valve was chosen for which individual patient. In addition, there were no echocardiographic follow-up data. Manghelli and collegues ${ }^{4}$ were therefore limited in their conclusions regarding the longevity of bioprosthetic valves in this population.

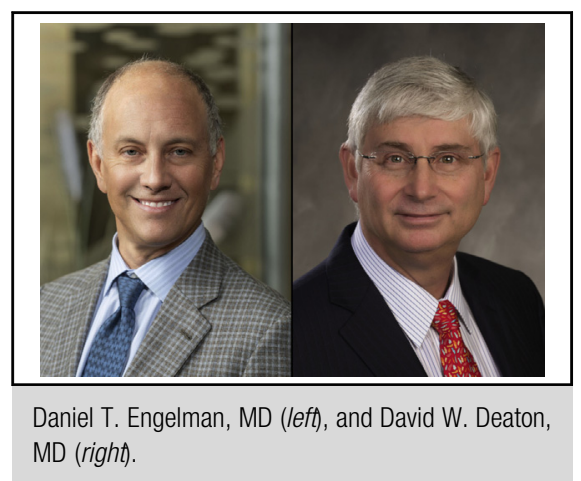

Central Message

Dialysis-dependent patients that require valve replacement surgery have such a dismal longterm prognosis that biologic valves (open or transcatheter) are probably warranted.

See Article page 805

Nonetheless, the life expectancy data and outcomes remain valid. The most important message from this exhaustive study was that only those patients in their 30s or 40s with New York Heart Association class I or II heart failure and without diabetes had a more than 50\% 5-year survival after valve replacement surgery. Manghelli and collegues ${ }^{4}$ suggest that only these younger, "relatively healthier" patients should be considered for mechanical valve prosthetics. The study also leads obviously to the question of whether patients with end-stage renal disease should be offered open surgical aortic valve replacement procedures at all, as more percutaneous options become available. It was recently demonstrated that dialysis-dependent patients have a lower mortality after transcatheter aortic valve replacement than after surgical aortic valve replacement. ${ }^{6}$ Future studies will need to validate these findings.

\section{References}

1. Ng JK, Li PK. Chronic kidney disease epidemic: how do we deal with it? Nephrology (Carlton). 2018;23(Suppl 4):116-20.

2. US Renal Data System. Annual Data Report. National Institutes of Health, National Institute of Diabetes and Digestive and Kidney Diseases; 2017. Available at: http://www.usrds.org/adr.htm. Accessed November 20, 2018.

3. Ahmad Y, Bellamy MF, Baker CS. Aortic stenosis in dialysis patients. Semin Dial. 2017;30:224-31.

4. Manghelli JL, Carter DI, Khiabani AJ, Gauthier JM, Moon MR, Munfakh NA, et al. A 20-year multicenter analysis of dialysis-dependent patients who had aortic or mitral valve replacement: implications for valve selection. J Thorac Cardiovasc Surg. 2019;158:805-13.e2. 
5. Brinkman WT, Williams WH, Guyton RA, Jones EL, Craver JM. Valve replacement in patients on chronic renal dialysis: implications for valve prosthesis selection. Ann Thorac Surg. 2002;74:37-42; discussion 42.
6. Alqahtani F, Aljohani S, Boobes K, Maor E, Sherieh A, Rihal CS, et al. Outcomes of transcatheter and surgical aortic valve replacement in patients on maintenance dialysis. Am J Med. 2017;130:1464.e1-11. 